\title{
The Influence of "Micro-Blog" Political Communication on Government Decision-Making
}

\author{
Wei WANG ${ }^{1, a}$, Chun-Yang WANG ${ }^{2, b}$ \\ ${ }^{1}$ School of Humanities and Social Sciences, North China Electric Power University, Director of \\ Beijing Energy Development Research Center ,Changping District, Beijing 102206, China \\ ${ }^{2}$ Postgraduate of School of Humanities and Social Sciences, North China Electric Power University, \\ Changping , Beijing 102206 China \\ a wwfancy@163.com, ${ }^{\mathrm{b}}$ wq2399@163.com
}

\section{Keywords: Micro-blog,Political Communication,Government Decision-making}

\begin{abstract}
At home and abroad in recent years, more and more government agencies and officials have opened certification micro-blog released relevant information in a timely manner and communicate with public opinion, as a service platform for the people and understand the way of the public opinion and interactive space. Government affairs micro-blog have played an important role in influencing the government's decision-making as an innovative political communication channels. The two-way political communication between government and people with government affairs micro-blog is advantageous to the scientific and democratic decision-making in the decision-making process.
\end{abstract}

\section{Introduction}

For micro-blog platform represented by Sina Micro-blog is rapidly applied in China,2010 is called "the first year of micro blogging". As a means of communication tools and mass media, micro-blog have an irreplaceable effect on the development of democratic politics, including expressing standpoint, revealing the truth, enhancing netizens participation and interaction, and guiding network public opinion. That deputy to the National People's Congress called for proposals by micro-blog and cause great repercussions in netizens is enough to prove the role of micro-blog in political communication. In recent years, micro blogging has already become a essential tool used by commissioners to observe public opinion, to solicit opinions and to interact with the netizens, we should create an exchange platform for collecting public opinion and clusting their wisdom by breaking the traditional way of network communication so as to provide references and exemplary roles for all parts of the country to carry out government micro blogging.

\section{The Rising and Characteristics of Micro-blog's Political Communication}

Under the situation that new network media has been increasingly developing, as a means of political communication, micro-blogging represents sudden appearance of a new force and becomes a new medium focused to talking heart to heart between the government and citizens. With micro-blog technology's further mature, micro-blog's characteristics will be more prominent in the political communication, especially in producing an effect on government decision-making.

\section{Summary of Micro-blog Political Communication}

Political communication is an interactive process with multiple locus. Communication is not an archery, but a dynamic process designed to achieve a certain result. This means that the government need seeking the support of the audience in the process of political communication. More important, the government should give people the opportunity to pass information back. As a modern organization, the government owns mainly four directions of communication: ascending, descending, parallel and oblique. Because of the bureaucratic hierarchy of information transmission, the political 
communication in our country is often faced with one-way delivery: upward or downward, so that the communication is limited, resulting in various problems.

Government micro-blogging mainly refers to the micro-blogging, on behalf of the government and officials, registered for public affairs and certified officially with authority and credibility. The government micro-blogging platform play the role of information dissemination in releasing news, providing services, understanding the public opinion and enhancing official and civilian interaction and so on.

With the rapid development of the Internet and the widely popular application of micro-blog, the role of micro-blog's political communication has been quickly highlighted. Micro-blog political communication refers to a behavior or a process that the government, people and social groups all transport, acquire and process political information through micro-blog, the specific media. A complete process of micro-blog political communication should includes at least three elements: the main body of communication, the channel of communication and the content of communication. Among them, the main body of communication is divided into the sender and receiver of political message, the communication channel is micro-blog, the communication content is political information. As shown in Figure 1.

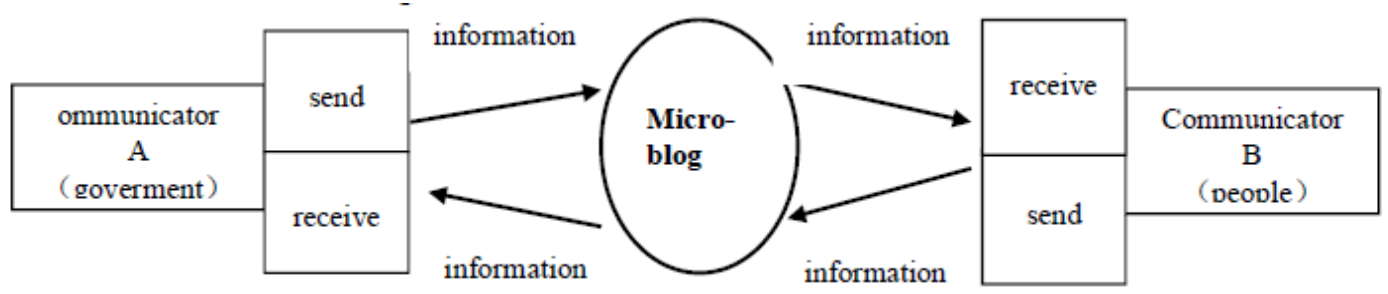

Figure 1 micro-blog political communication model

\section{Characteristics of Micro-blog Political Communication}

Generally speaking, political communication is composed of five elements, including the information sender, the recipient, the political information, the communication channel and the feedback. Micro-blog platform builds a new "Seconds back" communication platform, achieving real-time network interaction between government officials as a personal or collective and citizens. Compared with the traditional political communication, the micro-blog political communication has its own distinctive characteristics.

First, from the point of view of the relationship between communication subject and the communication process, micro-blog political communication enable communication subjects more equal, more free, more independent and more autonomous, fully releasing their personality and constantly fusing the boundaries between sender and receiver, so as to strengthen the interaction.

Second, from the point of view of communication channels, the directness, openness, rapidness, and globalization of micro-blog political communication makes information no longer suffer the layers of screening and interception from intermediators and makes information quickly exposed in front of the public with strong transmission capacity once commented, forwarded, re-commented and re-forwarded .

Third, from the point of view of the content transferring political information, the application of multimedia and hypertext impels micro-blog information cheaper and excessively massive. Powerful content makes micro-blog political communication process some characteristics such as cheapness effectiveness and pervasiveness. 


\section{Analysis on the Influence of the Micro-blog Political Communication on Government Decision-Making}

The interest demands of the people need to be clearly grasped by the government and have not get the protection until being transformed into public policy. But some interest demands have not been detected by the government in time, so it is necessary for interest expression. The process of interest expression is a kind of political communication process. The impact of political communication is reflected in the three steps of the government decision-making process: the agenda establishment, the policy planning and the policy legalization. And then, Micro-blog, as a new carrier of political communication, is also a double-edged sword, which has two sides. There are both favorable factors and unfavorable factors.

\section{The Favorable Factors of the Micro-blog Political Communication Influence on the Government Decision-making}

First of all, from the perspective of agenda building of government decision-making, it is conducive to rapid information interaction. After government departments and officials open the micro-blog and identify authentication, for all users, mutual information on hot social issues can be implemented anywhere through micro-blogging with government agencies and officials, for the government, the policy information can be transmitted to citizens promptly and accurately, in order to express opinion, to clarify the truth and to avoid information distortion; citizens can also feedback information directly to the government agencies or officials, such as personal opinions, demands and wishes. Political officially and overly formal official discourse in real society will be overcome, government agencies and officials will take a turn for users to narrow the distance between the government and the people, to promote trust and understanding of government and civil society and to achieve better communication and feedback effect, so as to timely improve the government decision-making.

Secondly, from the perspective of policy planning of government decision-making, what is benefited for reducing intermediate links of policy communication. The process of policy planning need experience several links: the establishment of policy objectives, the design of alternative schemes, the evaluation and selection of policy programs. ${ }^{[1]}$ The realization of these processes can not be separated from political communication. In this new era of micro-blog, it is more conducive for policy makers to the adoption of social power. The stronger social participation is, the more perfect policy will be. If formal channels of communication are not unimpeded, the citizens will seek non formal channels, which will lead to instability. ${ }^{[2]}$ In China's traditional political communication, communication levels are overly set and gradually transferred along the hierarchical process. The more levels through which information pass are and the longer the time is, the worse stability and reliability will be, which result in the declining of the spread effect of information, the attrition and distortion of contents, and the lowness of efficiency ${ }^{[3]}$.Through the micro-blogging, a new communication platform, the delivery of citizens' wills gets rid of the need for hierarchical steps and citizens could dialogue directly with government officials and even principal person in charge, in order to deliver our thoughts and opinions timely and accurately to government agencies and officials, thus further realizing the direct communication between the citizens and the government.

Third, from the perspective of policy legalization, it is conducive for improving the influence of citizens on decision-making. Compared to agenda building and policy planning, the government need show the achievements of the policy planning out in order to get more support. After the introduction and implementation of the policy, the people will naturally have their own new requirements and support for the new government decisions. Policy legalization may be much more formalized. ${ }^{[4]}$ In the process of traditional political communication, both as participating subjects of the communication, Inequality of government and civil status is common. The government is in the active position, who has the rights to decide methods and contents of communication; but the citizens is in a passive position, who can only be subject to the government's decision. Through the micro-blog platform, citizens cannot only express their views on the political issues of interest at any 
time, but also comment on the political views of others, which could be forwarded once recognized. Which makes citizens own the rights to speak as equal as the government and promotes equal exchanges on political issues both the government officials, experts and scholars and the public, so as to strengthen the communication of the government and the public, to ease the problem of information asymmetry between the government and the people, to improve the citizens' influence on the government decision-making, in favor for realizing the equality of citizens and the government in the political communication status.

\section{The Adverse Factors of the Micro-blog Political Communication Influence on the Government Decision-making}

First of all, the disorder and freedom of micro-blog's political communication may lead to the deviation of the government's decision. Every audience in Micro-blog is We-Media, which doesn't have its own editing system, so there may be some network rumors. Because of a lack of certain order and orderly supervision of the micro-blog as a form of political communication, adding its own characteristics virtualization, some citizens may irresponsibly share online in free and spread rumors, slander and attack the government publishing false information, initiating political demagoguery, manufacturing political chaos with the use of false identity, thus increasing the insecurity of political participation, even it may affect social stability seriously.

Secondly, the lack of certain institutional and legal protection restricts the government decision-making scientifically. With the continuous development of network applications, there is still a lack of effective systems and norms of the times in the standard of micro-blog's political communication. Therefore the rights and obligation of the communication subject are in a relatively fuzzy area in micro-blogging political communication, so do the access and procedures to information, which cause then on-standard of the micro-blog political communication, and then may affect negatively the government's scientific decision-making. Due to the high efficiency of information dissemination in the information age, some things has been spread in a large range before verified. When citizens express their political will, it is often very easy to click the icon "forward", but the political communication effect after that is what we can not expect, and even affect the government to make wrong decisions.

\section{Perfect Micro-blog Political Communication and Improve the Government Decision-making Scientifically and Democratically}

\section{Improve Technology Means and Make the "disorder" Micro-blog Upgrading to the "Dynamic" Micro-blog}

We should focus on technological upgrading and transformation, the all-media composed of newspapers, websites, micro-blogging, We Chat and other Apps achieve respective-combined and create the information communication service platform taking a news app as the core, in order to gradually realize functional integration. Only through a platform, trying to meet each user's overall needs from the information to sociality, entertainment and consumption, so as to achieve the goal of integration of traditional media and new media. The power of network public opinion is non-negligible, however, the force of dissemination is more irresistible, which sometimes lead people to completely lost the ability to identify themselves. This requires improving supervision technology of micro-blog running platform; blocking automatically the commentary and accounts which endanger homeland security with provocative characteristic; giving legal warning to serious cases. Meanwhile, we should strengthen the relevance and tracking of topics between government affairs and people's livelihood; provide more accurate recommendation about various topics related to politic and people's livelihood; Furthermore, we should make the means masking political reactionary speech more humanizing; upgrade the function of tracking, statistics and propagation path analysis to topics about government affairs and people's livelihood, so as to convenience enterprises to participate in the interactive-marketing activities about government affairs and people's 
livelihood, which is even provided to the account of the enterprise as the charging function, enhancing the program management function of political communication, for example, promoting interaction between citizens and government to motivate their inspiration for the national governance.

\section{Improve the Security of the System and Enhance the Credibility of the Government}

On China's legal system, the regulation of network supervision is not perfect. December 28, 2012, the decision on strengthening the protection of network information was considered and passed in the thirtieth meeting of the eleven session of the NPC Standing Committee and the real-name system is officially applied to the Internet management. meanwhile, it is also questioned by many people who think the real name system will impede micro-blog and network anti-corruption, who also feel no guarantee as the Internet users when deliver a lot of speeches. However, the introduction of the subsequent regulations further explains that users' speeches are released anonymously in the network, though users themselves are subject to real-name registration. This can not only guarantee the legitimate speech rights of Internet users, but also avoid the occurrence of rumors to a certain extent. In addition, the reason to the spread of rumors firstly is that there is no authoritative and credible institutions coming out to clarify things and reduce the public's doubts in the first time when thing happened, but allow a variety of speech delivering everywhere, then the spread of rumors will infiltrated political communication process in some degree. Secondly, the disseminators with irrational emotions believe no the interpretation of the authorities, and even guide other two-time communicators to refuse and resist the authoritative department 'interpretation. Therefore, to let citizens trust the government, we must improve the government mechanism. If each event has a lot of witnesses and these people use micro-blog to release information at the same time, the different views will form supplement each other ${ }^{[5]}$. When all the insiders' point of view get together, it will lead to the reproduction of the truth with forming the relationship of mutual complement and mutual correction. This will build micro-blog as a platform of high credibility that can verify and crush rumors. Therefore, the open, the transparent is the primary condition. The closure is not an effective means to control the rumors, contrarily, it may promote the continued expansion of rumors, and then affect the government decision-making. Government should timely announce the truth to citizens before citizen shave doubts or misunderstanding, give citizens more democratic rights and the right to know, strength publicity efforts to the rule of law and ethics of morality, foster a sense of mission and responsibility from the micro-blog audience, in order to better carry out political communication and government decision-making.

\section{Build the Quality Platform and Make the Public Opinion Becoming the Positive Energy to Guide the Government Decision-making.}

Civil public opinion has always been an important force to guide the government's decision-making. We should take advantage of micro-blog to arouse civic responsibility, and making them actively concern about politics, people's livelihood, and the country. Currently micro-blog users can be divided into two levels, one is the "big V" or celebrity micro-blog. Another category is the ordinary micro-blog users. But the big $\mathrm{V}$ or celebrity micro-blog is often fast forwarded by a large range, which shows that the credibility of the source of information can affect people's judgment on the true and false information. The content of "Big V" or celebrities' micro-blog will more likely get the audience's approval, so that the audience has lost the basic judgment. thus as experts in various fields, the well-known and the famous who not only master resources, but also own quality point of view shall reasonably reflect the civilian demands and the problems existing in the people's livelihood; call for civil topics' relative access to government decision-making; try to convince the masses using reason and data to strengthen political communication; accept heartly and sincerely the opinions and dissatisfaction from the masses; present the leadership proposals aiming at government decision-making.

For ordinary micro-blog users, it is necessary to restrain the waterfall effect ${ }^{[6]}$ and group polarization $^{[7]}$ from their own communication psychology. Group polarization does not refer to group 
opinions divided into two opposite factions, but refers to the opinions' the first inclination further strengthened. The mass polarization effect is very obvious in the network communication. A person choosing wrong camp will lead to a group of people standing in the wrong camp. Which requires the general micro-blogging users do not blindly accept some viewpoints when participating in political communication with the ability to distinguish between right and wrong and the spirit to pursue the truth, and also do not to cultivate extreme ideology and unkind words as the result of their own politics being chased or criticize and abuse in the style of forwarding, topping, commenting and other forms. Meanwhile, the general micro-blog users are not also expected to bring the dark face of network to life, and do not use "negative energy" behavior to hinder the government decision-making process. In the public sphere, the network, the citizens' ethics and quality need to be increasingly strengthened. As a new carrier of communication, micro-blogging do not make the audience's individual consciousness as isolated as the preceding non-network era. In the view of one thing, due to the audiences themselves participating in the second communication, their emotion of the sympathetic visage is stronger than the previous, and then they can share self consciousness with other audiences to impact the government's decisions. So for the audience itself, it is essential to deeply understand the importance of the image as a two-time communicator. We should not only make full our rights to freedom of speech that conferred by laws, but also do well the checking to prevent the wanton dissemination of rumors before the spread of information.

\section{Conclusion}

In short, as a new product of the information age, micro-blog politics is the inevitable trend of the development of the times, in the same time, in the condition of technology, system security and psychological basis, micro-blog politics will be able to promote the development of citizen's political participation and provide support for the stability of the our country's overall reform situation. Therefore only if we can understand micro-blog more soberly and rationally, make full use of micro-blog's advantage, face bravely various difficulties it brings and foster strengths and circumvent weaknesses, in order to let the micro-blog play the real role to support and promote citizen's political participation, and then to boost the construction of socialist democratic politics, which makes that citizens participate in democratic politics and influence the government's decision-making through micro-blogging becomes a new way of political communication.

\section{Acknowledgment}

This paper is supported by Special Items Fund of Beijing Municipal Commission of Education and supported by the Fundamental Research Funds for the Central Universities.

\section{References}

[1][America] David Easton, Wang Puqu analysis [M]. translation system of political life. Beijing: Huaxia publishing house, 1989.

[2][America]F - J - Goodnow. Political and administrative [M]. Yang estimate translation. Beijing: Huaxia publishing house, 1987.

[3]Ma Xiaojing. Political communication from the perspective of government affairs under the micro-blog analysis [D]: Master's thesis. Jilin: Jilin University, 2014.

[4]Wang Puqu. Political Science Foundation [M]. Beijing: Peking University press, 2003.

[5]Wang Jinshui. Citizen network political participation and political stability [J]. China's administrative 
[6]Many times information issued by the psychology is very calm, but the outgoing information by others to accept by the calm reaction, resulting in information the recipient's attitude and behavior change, this kind of psychological phenomenon called waterfall effect.

[7]At the time of the incident, regardless of the initial opinions toward the direction in which, through group discussion will be strengthened, results not only group concept to the extreme, even the individual also occurred in the the transfer, this is a group polarization effect. 